\title{
BALANCING INTERNATIONAL INSURANCE PORTFOLIOS AND EXCHANGE RISKS *
}

\author{
Tamir Agmon and Yehuda Kahane
}

\begin{abstract}
This paper examines the balancing of the investment and liability portfolios of a (re)insurance firm operating in the international market. The model captures two effects which are ignored by traditional analysts.

(a) According to the Interest Parity Theoren, the expected changes in the exchange rates should already be reflected in the expected rate of return on foreign investments. Therefore, an insurer operating in a perfect market should be indifferent to the currency denomination of its financial assets.

(b) A second effect which has often been ignored is related to the additional risk resulting from the unexpected fluctuations of the exchange rates.

The multi-index model suggested in this paper is capable of capturing these effects. The model can be used to examine and analyze alternative policies of the firm operating in international markets. For example, the model can be used to examine whether an insurer should take positions in certain currencies, or rather take a "full-hedge" policy.
\end{abstract}

\section{IN'TRODUCTION}

A world-wide diversification of national risks is one of the basic goals of the insurance industry. As a result, insurance companies, particularly those specializing in reinsurance, are deeply involved in international transactions to the extent that some may be regarded as true multinationals. International transactions are carried out in a variety of currencies, and, therefore, the performance of international insurance companies depends to a large extent on what happens to the exchange rates.

The flexible exchange rates system introduced in the developed countries in the early seventies led to more frequent fluctuations in the exchange rates of all currencies in terms of a given numeraire. It is, therefore, not surprising that insurers expressed deep concern about the new regime of exchange rates and its effects on the recorded profitability of their business. Most of the analysis which has appeared in trade journals concentrates on the effects of changes in the exchange rates on the expected profitability and disregards the compensatory effect of the difference in the rates of return on financial assets denominated in different currencies. In addition, only slight attention is given to the way in which the fluctuations of exchange rates contribute to the riskiness of the future earning streams of the insurer.

This paper has both positive and normative aims. On the positive side, the effects of fluctuations in the exchange rates on the expected value and the variability of insurers' income streams are examined. The normative part of

* Presented at the 14th ASTIN Colloquium, Taormina, October 1978 . 
the paper deals with the simultaneous balancing of the insurance and the investment portfolios for an insurance company operating in the international market.

Section 2 discusses the effects of changes in the exchange rates on the expected profitability. It is argued that such effects are partially captured through market equilibrium mechanism, so the firm can remain indifferent to such changes. Section 3 discusses the contribution of the exchange rates to the riskiness of the firm's portfolio, and Section 4 suggests the model for balancing the insurance and investment activities. The article is summarized with some concluding remarks in Section 5 .

\section{EXCHANGE RATES AND EXPECTED PROFITABILITY}

Changes in the exchange rates may affect the expected rates of return on investment and underwriting activities. Such effects, which are recognized in trade journals ${ }^{1}$, can best be demonstrated through the analysis of a simple numerical example. Assume an investment of $\$ 100$ in the U.S. which returns $\$ 120$ at the end of the year. From the point of view of an American firm, the profitability of this activity is $20 \%$. However, from the point of view of a U.K. firm, whose reference currency is the Pound Sterling, the rate of profit depends on an additional factor-the rate of exchange. If the rate of exchange at the beginning of the period was $f 1=\$ 2.50$, and at the end of the year it was $f_{1}=\$ 1.70$, the profit would be $76.5 \%{ }^{2}$. Similarly, such a movement of the exchange rate would lower the rate of profit expected by a U.S. firm investing in a U.K. project. In fact, a profitable project for the British firm may be a losing project from the point of view of an American investor 3 .

In the same manner, exchange rates movement can affect the performance of an underwriting activity. For example, assume an insured American risk with a premium of $\$ 100$ and assume that claims (and expenses) equal $\$ 80$. Thus, a U.S. insurer expects a $20 \%$ underwriting profit from this policy. A British reinsurer, accepting a portion of this risk (under a proportional reinsurance treaty), would expect a much higher underwriting profit $(76.5 \%)$.

The above examples create the impression that exchange risks must be the major worry of insurance companies. It is our contention that this would be an incorrect perception of the situation. Interest rates differentials would, in equilibrium, capture the expected changes in exchange rates. Thus, the

1 See for example in the NRG's Quarterly Letter (1974).

2 This figure has been derived in the following way: a $\notin 4^{\circ}$ investment (equivalent to $\$ 100$ at the beginning of the year) returned $£ 70.59$ ( $\$ 120$ at the end of the year). Thus, the profitability of the U.S. project, from the point of view of the U.K. firm would be $76.5 \%-((70.59-40) / 40)$.

"Assume a l.K. investment of $f 100$, which at the end of the year yiclds $f_{1} 120$. Thus a U.K. investor expects a rate of return of $20 \%$. The U.S. investor invests $\$ 250$, but yields $\$ 204(1.70 \times 120)$ i.e., his expected rate of profit is minus $18.4 \%((204-250) / 250)$. 
firm should pay attention only to the unexpected changes, at least with regard to its investment portfolio. The following paragraphs are used to claborate this point.

Economic theory indicates that, in the absence of transaction costs and any other barriers to free international capital flows, current and expected future exchange rates in different countries will be consistent. The term "consistent" means here that any investor, private or institutional, is indifferent to the currency in which his holdings are denominated, as the expected changes in the exchange rates are compensated for by interest differentials. This indifference is expressed by the Interest Rates Parity Theorem (IRPT) which relates interest rate, spot exchange rates, and forward exchange rates. The relationship between interest rates and exchange rates is based on the close connection between interest rates and inflation, and future exchange rates and inflation. Moreover, in a world without any barriers to free movement of capital and with sufficient information, the future change in the exchange rate of country $i$ in terms of the currency of country $j$ will equal the differential inflation in the two countries. The above relationships can be demonstrated by the following equations:

Let $P_{i t}$ be the price level of (tradable goods) of country $i$ in period $t$ and $X_{i j, t}$ be the exchange rate between the currencies of country $i$ and country $j$ in period $t$. The relation between the change in the exchange rates and the changes in the price level (the inflation) in the two countries is given by equation (1) below:

$$
\frac{X_{i j, t}}{X_{i j, t-1}}=\frac{P_{i, t} / P_{i, t-1}}{P_{j, t} / P_{j, t-1}} .
$$

Equation (1) is known as the Purchasing Power Parity. The IRPT postulates that:

$$
\frac{X_{i j, t-1}-F_{i j, t}}{X_{i j, t-1}}=\frac{r_{j t}-r_{i t}}{1+r_{j t}}
$$

where $F$ is the forward exchange rate at $t-1$ due at $t$, and $\gamma_{t}$ is the interest rate observed at $t-1$ on bonds redeemable at $t$.

Irving Fisher suggested many years ago that the observed nominal interest rate contains two components: (a) the real interest rate (pure time preference); and (b) the expected rate of inflation over the comparable holding period. Thus, $r_{t}$, the interest rate in any given currency, can be presented as:

$$
1+r_{t}=\left(1+r_{t}^{*}\right) P_{t}^{e} / P_{t-1}
$$

where $r_{t}^{*}$ is the real interest rate and $P_{t}^{e}$ is the expected price level at $t$. 
By substituting (3) into (2) for currencies $i$ and $j$ and rearranging terms, we obtain :

$$
\frac{F_{i j, t}}{X_{i j, t, 1}}=\frac{\left(1+r_{i t}^{*}\right) P_{i t}^{e} / P_{i, t-1}}{\left(1+r_{j t}^{*}\right) P_{j t}^{e} / P_{j, t-1}}
$$

Assuming that the time preference is identical among countries, i.e. $r_{i t}^{*}=r_{j t}^{*}$, equation (4) becomes identical to (1) in an expected form. In other words, given our assumption on no-barriers-market, the difference in the current interest rates for the same holding periods in two currencies will reflect fully the expected future change in the exchange rate between these two currencies. Thus, the investor is indifferent with regard to the denomination of his financial (riskless) assets.

The Interest Rates Parity Theorem is usually specified only in terms of riskless assets in the respective currency. However, the same principle holds when risky assets are concerned, provided that they belong to the same riskclass. The term "risk-class" was introduced by Modigliani and Miller (1958). The basic requirement is that the distributions of returns of any two assets within the same risk-class will be perfectly positively correlated (a correlation coefficient of +1 ). Given this assumption, and assuming furthermore that the distribution of returns in terms of foreign currency of the asset in question is independent from the distribution of the future changes in the exchange rate, the IRPT holds for risky assets as well as for riskless assets. The implied relationship can be expressed as follows:

Let $\tilde{P}_{k i t}$ be the unit price of an asset in risk-class $k$ in currency $i$ at time $t$ to maturity $T$ periods hence. In other words, $\breve{P}_{k i t}$ is equal to the price of a discounted bond in currency $i$ for $T$ periods. Let $P_{k j t}$ be the price of an asset in the same risk-class in terms of currency $j$, where the price is specified in terms of currency $i$. Given our assumptions on the risk-class, and the additivity property, every capital asset denominated in currency $j$ can be decomposed into two parts: The first part represents the distribution of returns of the underlying economic activities expressed in terms of currency $i$, the numeraire currency. The second part is the non-numeraire currency asset which represents the distribution of returns associated with the future value of currency $j$. The price of the non-numeraire currency asset is:

$$
P_{j t}=P_{k j t}-P_{k i t} \text {. }
$$

For example, $P_{k i t}$ may be the U.S. dollar price of a bond in risk-class $k$ with 3 periods to maturity. $P_{k j t}$ is the U.S. dollar price of a bond with three periods to maturity in a similar risk-class where the obligation is denominated in Deutsche marks. $P_{j t}$ is the U.S. dollar price of the implicit Deutsche mark asset for three periods. $P_{j t}$ is the price that the investor is willing to pay for a future contract, i.e. for having one unit of Deutsche marks three periods 
from now. The return of the non-numeraire currency asset can be estimated by a time series of the price relative $R_{k t}$ where:

$$
R_{k t}=P_{j(t+1)} / P_{j t} .
$$

Many international investors, individuals and firms alike, have demonstrated that they are not indifferent with regard to the denomination of their assets and liabilities. An obvious reason for this behavior is that the world financial markets are not perfect and many barriers to the free flow of capital do exist. Therefore, the above equilibrium condition does not necessarily hold, and the multinational firm may prefer to hold its assets (and have its liabilities) in a certain mix of currencies.

Another reason why the multinational firm may not be indifferent to the exchange rate problem is related to the element of uncertainty. The IRPT model is based on the market's prediction of the expected future rate of inflation. As in the case of any other random variable, the expectation does not fully describe the project, and we should account for the risk involved by looking at some dispersion measure such as the variance. The potential exchange risk is relevant particularly to insurers and reinsurers, as they are susceptible to large losses due to the nature of the insurance transaction and taking additional risk is not always desirable.

Thus, there is a need for a model to capture the unique risk of international operations, one which would guide management with regard to balancing exchange risk in the context of a total portfolio. Such a model is presented in the following sections.

\section{EXCHANGE RISKS AND MULTINATIONAL INSURERS}

The effects of the fluctuating exchange rates are not limited to the expected profitability. Since the rate of exchange can be regarded as a stochastic variable, it may also affect the variability of the rates of return on various activities, thus affecting their risks. This effect turns out to be even more complicated once the return on each activity is regarded as stochastic in itself.

Switching from the local arena to the international market opens new opportunities but adds new risks. One risk, unique to the international market, is the exchange risk. Exchange risk is defined in terms of the unanticipated movements of the exchange rate of a given currency in terms of the relevant reference, or numeraire, currency. Exchange risks may affect the distributions of the rates of return on both underwriting and investment activities. Thus, in moving internationally, this additional specific risk has to be considered in the portfolio selection process of the insurer.

The evaluation of exchange risk may differ as the reference currency (the "home currency") differs. Therefore, local firms may face an entirely different set of financial ventures than the foreign firm, though they both face the same original investment and underwriting projects. 
Insurance companies deal with risky situations and their future profits are uncertain. One of their major problems is to design a proper portfolio of assets and liabilities which complies with their risk preferences given a certain rate of return. This is a complex problem, since all the possible relationships between all investment and underwriting activities must be considered simultaneously. The problem is even more complex when the relevant market for the insurer is the international rather than the domestic arena, since the same pure risks may be regarded as having different levels of financial risks (according to their currency denominations) ${ }^{4}$.

A possible way which insurers may use in order to reduce the effects of currency fluctuations is by holding investments in many currencies. One common policy is to hold investments to cover the obligations in the same currency, i.e. the firm is trying to offset some of the currency risk by hedging. This is not always possible in insurance markets, since the needs for offsetting reserves in a certain currency are not fully predictable due to the stochastic nature of the claims process. This subject is discussed at some length in the next section.

\section{THE INSURER'S PORTFOLIO PROBLEM IN THE INTERNATIONAL MARKET}

The financial literature suggests techniques for selecting a portfolio of assets in an efficient way. Efficiency is defined as having a portfolio with a minimum level of risk for a given expected rate of return. The minimum level of risk is accomplished by diversification. The risk of a diversified portfolio is generally smaller than the sum of the individual risks (measured by the variability of the rates of return) for any given level of expected return ${ }^{5}$. Several models for the optimization of the composition of the entire balance sheet (asset and liability portfolios) have recently been proposed in insurance literature ${ }^{6}$. These models are based on the extension of the Quadratic Programming Model which is used in the selection of pure investment portfolios; see Markowitz (1952). Recently, KaHANE (1977) suggested the use of the "diagonal" model developed by SHARPE (1963) as an alternative device.

We suggested that the more complicated problem of choosing an inter-

${ }_{4}^{4}$ The efficient portfolio composition may depend on the reference currency. It is possible that insurers and reinsurers in different countries (and with different reference currencies) will select different portfolios when they face the same original set of pure risks. Local ventures may be perceived as less risky by the local firm. This may be one of the explanations for a growing isolation of the local insurance market that hinders the optimal geographical spreading of risks, as a protection against local catastrophes.

5 It is often argued that firms must be risk neutral and that investors' risk aversion would be expressed through the valuation of the firm's shares. However, the special attitude of management and insurance regulators toward the risk of ruin may justify the assumption that insurers are risk averse in the Markowitz sense.

" See, for example, Agnew, et. al. (1969), Ferrari (1968), Haugen and Kroncke (1970), Kahane and Nye (1975), Krouse (1970), and Quirin, et. al. (1974). 
national portfolio, where exchange risks do exist, can be solved by means of a multi-index model. The multi-index model was originally proposed by COHEN and Pogue (1967) as an alternative algorithm for the classical portfolio selection problem. This approach was used in the insurance context by BIGER and KAHANE (1978) and in the context of the international capital markets by AGMON (1972), and AGMON and Lessard (1977).

Assume that the insurance company can underwrite policies in $m$ insurance lines and that it considers investment in $n-m$ assets. The return on each activity $i$ is assumed to be a random variable with approximately normal distribution.

The rate of return on equity, $\tilde{y}$, is a linear combination of the specific returns and thus $\tilde{y}$ is normally distributed ${ }^{7}$ :

$$
\tilde{y}=\sum_{i=1}^{m} x_{i} \tilde{u}_{i}+\sum_{i=m+1}^{n} x_{i} \tilde{r}_{i}
$$

where $\tilde{u}_{i}=$ rate of profit on insurance line (percent of premium) for $i=1, \ldots, m$;

$\tilde{r}_{i}=$ rate of return on investment $i$ for $i=m+1, \ldots n$;

$x_{i}=$ ratio of investment in activity $i$ to total equity, for $i=m+1$, $\ldots n$, and the ratio between the premiums in line $i$ to the equity, for $i=1, \ldots m$.

Assume now that the stochastic variable representing the return on each activity is composed of a few elements. The first element is a constant, representing the expected return for a highly diversified portfolio of such activities, where no exchange risk prevails. The second element is a random variable with a zero expected value and a known variance. This element represents the stochastic deviations from the expected value, where no exchange risk prevails. The third element represents the effects of the change of the exchange rates.

This process can be described formally in the following way: Assume that there are $s$ non-reference currencies, with periodical fluctuations $\tilde{l}_{k}$, where $\tilde{l}_{k}$ represents the change of exchange rate $k$. The underwriting profit of activity $i$ is related to these currency indices with a coefficient $B_{i k}$. (Typically, each transaction is made in one currency, so that only one $B_{i k} \neq 0$ and all other coefficients are zero.) The underwriting profit can thus be described as:

$$
\tilde{u}_{i}=A_{i}+\sum_{k=1}^{\infty} B_{i k} \tilde{l}_{k}+\tilde{C}_{i} \quad(i=1, \ldots, m)
$$

where $\tilde{C}_{i}$ is random. An additive model is assumed as a first approximation.

7 The normality assumption is needed in order to justify the use of the mean-variance approach for selection of efficient portfolios. This assumption is not as strong as it may appear in the first reflection. Each activity is in itself a portfolio of many similar risks (e.g., many insurance policies in the same line), and the rate of profit on such an aggregated activity can be assumed normal by the Law of Large Numbers. 
Quite a similar model can be suggested for a multiplicative case, where logarithms are used.

Similarly, the return on investments can be described as:

$$
r_{i}=A_{i}+\sum_{i=l} B_{i k} \tilde{l_{k}}+\tilde{C_{i}} \quad(i=m+1, \ldots, n)
$$

The following statistical assumptions are employed for both underwriting profits and investment returns:

$$
\begin{array}{ll}
E\left(\tilde{C}_{i}\right)=0 & (i=1, \ldots, m, \ldots, n) \\
\operatorname{Var}\left(\tilde{C}_{i}\right)=Q_{i} & (i=1, \ldots, m, \ldots, n) \\
\operatorname{Cov}\left(\tilde{C}_{i}, \tilde{C}_{j}\right)=0 & (i \neq j . \quad i, j=1, \ldots, n)
\end{array}
$$

i.e. the returns on investments and the underwriting profits are assumed to be related only through the indices $\tilde{l}_{k}$. The disturbances $\tilde{C}_{i}$ are assumed random and uncorrelated so that they can be diversified away by holding a portfolio.

The fluctuations of exchange rates are assumed to be random and to fulfill: (9)

$$
\tilde{l}_{k}=A_{n+k}+\tilde{C}_{n+k}
$$

i.e. they have two elements, one random (with a zero expected value) and one constant (with no risk).

Assuming that

$$
\begin{aligned}
& E\left(\tilde{C}_{n+k}\right)=0 \\
& \operatorname{Var}\left(\tilde{C}_{n+k}\right)=Q_{n+k} \\
& \operatorname{Cov}\left(\tilde{C}_{n+k}, \tilde{C}_{n+l}\right)=\sigma_{k l} \\
& \operatorname{Cov}\left(\tilde{C}_{n+k}, \tilde{C}_{i}\right)=0 \quad i=1, \ldots, m, \ldots, n,
\end{aligned}
$$

the return on equity in (5) becomes:

$$
\begin{aligned}
y & =\sum_{i=1}^{n} x_{i}\left(A_{i}+\dot{\sum}_{k=1} B_{i k} \tilde{l}_{k}+\tilde{C}_{i}\right)= \\
& =\sum_{i=1}^{n} x_{i}\left(A_{i}+\tilde{C}_{i}\right)+\sum_{i=1}^{n} x_{i} \dot{\sum}_{k=1} B_{i k}\left(A_{n+k}+\tilde{C}_{n+k}\right)= \\
& =\sum_{i=1}^{n} x_{i}\left(A_{i}+\tilde{C}_{i}\right)+\sum_{k=1} \sum_{k=1}^{n} x_{i} B_{i k}\left(A_{n+k}+\tilde{C}_{n+k}\right) .
\end{aligned}
$$




\section{Denoting}

(11) reduces to

$$
\tilde{y}=\sum_{i=1}^{n+s} x_{i}\left(A_{i}+\tilde{C}_{i}\right)
$$

with expected value

$$
E(\tilde{y})=\sum_{i=1}^{n+\bullet} x_{i} A_{i}
$$

and variance

$$
\operatorname{Var}(\tilde{y})=\sum_{i=1}^{n} x_{i}^{2} Q_{i}+\sum_{k=1}^{\dot{\Sigma}} \sum_{i=1}^{\dot{S}} x_{m+k} x_{m+l} \sigma_{l k^{*}}
$$

Consider an insurer whose objective is to minimize the variance of the return on equity for every level of expected value. His problem is to identify the mix of investments and underwriting activities, i.e. the set of $x_{i}$ 's which minimizes a lagrangian $L$ :

$$
\text { Minimize } L=\operatorname{Var}(\tilde{y})-\lambda E(\tilde{y})
$$

subject to the constraints:

$$
\begin{gathered}
x_{i} \geqq 0 \quad(i=1, \ldots, n) \\
x_{n+k}=\sum_{i=1}^{n} x_{i} B_{i k} \quad(k=1, \ldots, s) \\
\sum_{n=m+1}^{n} x_{i}=\sum_{i=1}^{m} x_{i} g_{i}+1 .
\end{gathered}
$$

Efficient balance sheet compositions are obtained by solving equation (16) subject to the constraints (17) through (19). The set of inequalities in (17) is the usual set of non-negativity constraints. Equation (19) is the balance sheet constraint. It states that total assets minus total liabilities must equal equity. The term $\sum_{i}^{m} x_{i} g_{i}$ reflects total liabilities generated by the insurance company per dollar of equity. The coefficients $g_{i}$ represent the amount of reserves generated by one premium dollar in insurance line $i^{8}$. Note that the $x_{i}$ 's are expressed on a percent of equity capital basis and therefore the sum in (19) must equal 1. Finally, the term $\sum^{n} x_{i}$ represents total investment (assets) per a unit of equity.

8 The liabilities of insurance companies are generated by collecting premiums in advance, before they are earned, and by the delayed nature of payments of claims. The size of $g_{t}$ in different insurance lines depends on the velocity of claim settlements. 
Equation (18) reflects the technical relationships defined in (12) and has an important economic meaning: $x_{n+k}$ represents the overall net investment in currency $k$ through both the investment and underwriting activities (assets and liabilities). This is so since each activity creates an indirect holding in the various currencies, according to the value of the coefficients $B_{i k}$. The amount of currency $k$ held may be positive or negative, according to the specific signs of these coefficients. The proportion $x_{n+k}$ represents the weighted sum of all these holdings for currency $k$. $x_{n+k}$ is determined as a by-product of the optimization process, and its size indicates the effects that a change in the exchange rate of this particular currency will have on the firm's portfolio.

The fluctuations of exchange rates of various currencies tend to be correlated, and the correlation tends to be highly positive within certain currency areas (e.g. the Common Market or the Sterling Bloc). Optimal policy, therefore, can be specified in terms of a sub-group of representative currencies, where the currencies are chosen in such a way as to minimize the co-variability among themselves. Using these representative currencies is equal to using a set of orthogonal indices, which reduces the problems of multi-collinearity which would arise when the coefficients of equations (6) and (7) are estimated by means of regression analysis. In addition, the use of representative currencies has some obvious managerial advantages, as it involves a reduced number of policy variables.

\section{SUMMARY AND CONCLUDING REMARKS}

The traditional analysis of the performance of large international reinsurers in an environment with fluctuating exchange rates typically concentrates on the effect of exchange rates on profitability of the firm. The multi-index model suggested in this paper captures and analyses two additional effects.

One of these effects is the compensating effect of return on investments denominated in foreign currency. According to the Interest Rates Parity Theorem, the expected rates of return on foreign investments reflect the expected change in the exchange rate. Therefore, a firm operating in a perfect market would be indifferent to currency denomination of its financial assets. The firm should consider only the unexpected element in the exchange rate movements.

A second element which has been disregarded in the traditional analysis of multinational insurers is related to the exchange risks. Exchange rate movement can be regarded as a stochastic process. Thus, the uncertainty in the exchange rate contributes to the variability of the return on each investment and underwriting project. The firm should therefore be aware of this new element of risk while constructing its investment and insurance portfolios.

The multi-index model suggests a way of accounting for these two effects. This is achieved by considering each activity (insurance or investment activity) 
as a combination of a few components: First, a constant element $\left(A_{i}\right)$ which represents the expected rate of return on the activity, where exchange rates are assumed fixed. A second element $\left(Q_{i}\right)$ represents the risk of each project under the same situation. In addition, each activity is related to the changes in various exchange rates (through the coefficients $B_{i k}$ ). Representing the rate of return in such a manner facilitates the identification and analysis of the interest parity and the exchange risk effects.

The multi-index model, besides its ability to handle explicity the above ideas can be used as a managerial technique for the simultaneous optimization of insurer's entire balance sheet (asset and liability portfolios). The optimization process takes into consideration the regular investment and underwriting risks and, in addition, considers exchange risks. This model can serve as an important tool for managerial decision-making, once the management exante estimates for the coefficients are given.

The model enables identification and measurement of the exchange risk, which is implicit in each portfolio composition: Each risky activity is a combination of random variables, and some of them represent exchange rates movements (in terms of the reference currency). Summing up all the variables related to a certain currency over all activities gives the net "investment" in this currency (equation (12)) and reflects the firm's vulnerability to its fluctuations. By analysing this term it is possible to examine alternative exchange rate policies.

A common practice in the international capital market is a "full hedge" policy, which is attained when the insurer has a zero net position in any nonreference currency. This policy means that, for any liability in a foreign currency, there exists an asset which exactly balances it. In the insurance industry, this is rarely, if at all, possible, since it is impossible to determine the exact amount of cash needed to cover future claims. The firm can solve part of this problem by holding a reserve reflecting the expected losses, but this does not give full protection against the fluctuations around the expected losses. The problem is even more complicated since the insurer, who pays claims in many currencies, must protect the real value of his profits. Using the model with real data would probably show that a "no exchange risk" policy is not necessarily efficient; exchange risks must be considered simultaneously with the other risks of the firm, and it is not inevitable that the efficient solution will involve net (positive or negative) holdings of a certain currency.

In cases where the Interest Rate Parity Theorem does not hold (due to market imperfections), the firm may not remain indifferent to the selection of its reference currency. In such cases, local risks may be considered less risky than other foreign risk (despite the fact that they represent similar pure risks). Thus, the local and the foreign insurers may hold completely different portfolios even though they face the same risks. The differences in the perception 
of risks, due to the effects of exchange rates, may serve as an incentive for isolation of national insurance markets. If this effect does in fact exist, it would be a question of utter importance for the insurance industry, as it would be a barrier to the geographical spreading of national catastrophic risks.

The selection of the firm's reference currency may be another important problem in a market with barriers, since it may affect the reported profitability of the firm. The accounting problems which arise in such a world, and their implications for the taxation of the firm, and other related topics are currently being studied by the authors.

Tel Aviv University, Tel Aviv, Israel.

\section{REFERENCES}

Agmon, T. (1972). The Relations Among Equity Markets: A Study of Share Price CoMovements in the U.S., U.K., Germany and Japan, Journal of Finance, 27 (2), $839-855$.

Agmon, T. and D. R. Lessard (1977). Investor Recognition of Corporate International Diversification, Journal of Finance, 32 (3), 1049-1055.

Agnew, N. H., R. A. Agnew, J. Rasmussen and K. R. Smith (1969). An Application of Chance Constrained Programming to Portfolio Selection in a Casualty Insurance Firm, Management Science, 15 (10), B512-B520.

Biger, N. and Y. Kahane (1978). Balance Sheet Optimization for Non-Life Insurance Companies-An Extension, The Journal of Insurance Issues and Practices, 2 (1), $71-81$.

Conen, K. J. and J. A. Pogue (1967). An Empirical Evaluation of Alternative PortfolioSelection Models, Journal of Business, 40 (1), 166-193.

Ferrari, J. R. (1968). The relationship of Underwriting, Investment, Leverage and Exposure to Total Return on Owners Equity, Proceedings of the Casualty Actuarial Society, 55.

Fisher, I. (1931). The Theory of Interest, MacMillan, New York.

Haugen, R. A. and C. O. Kroncke (1970). Optimizing the Structure of Capital Claims and Assets of a Stock Insurance Company, The Journal of Risk and Insurance, 37 (1), 41-49.

Kahane, Y. and D. Nye (1975). A Portfolio Approach to the Property Liability Insurance Industry, The Journal of Risk and Insurance, 42 (4), 579-598.

Kahane, Y. (1977). Determination of the Product Mix and the Business Policy of an Insurance Company: A Portfolio Approach, Management Science, 23 (10), 1060-1069.

Krouse, C. G. (1979). Portfolio Balancing Corporate Assets and Liabilities with Specific Application to Insurance Management, Journal of Financial and Quantitative Analysis, 5, 77-105.

Lessard, D. R. (1976). The Structure of Returns and Gains from International Diversification, in Elton and Gruber, Eds., International Capital Markets, North Holland.

Markowitz, H. (1952). Portfolio Selection, Journal of Finance, 7 (1), 77-91

Modigliani, F. and M. H. Miller (1958). The Cost of Capital, Corporation Finance and the Theory of Investment, American Economic Review, 48 (2), 261-270.

Nederland Reassurance Group (1974). Monetary Problems for Professional Reinsurers and Currency Affairs, NRG Quarterly Letter, 19, 1-28.

Quirin, D. G. ET. AL. (1974). Competition, Economic Efficiency and Profitability in the Canadian Property and Casualty Insurance Industry, Insurance Bureau of Canada, Toronto.

Sharpe, W. F. (1963). A Simplified Model for Portfolio Analysis, Management Science, 9 (2), 277-293. 